\title{
Analysis of the impact of Combined Cycle in the energy transition
}

\author{
Alberto Vannoni ${ }^{1}$, Daria Belotti ${ }^{1}$, Alessandro Sorce ${ }^{1, *}$ and Aristide Fausto Massardo ${ }^{1}$ \\ ${ }^{1}$ University of Genoa, Thermochemical Power Group, 16145 Via Montallegro 1, Genova, Italy
}

\begin{abstract}
The energy transition of the Italian electrical sector is balancing the objective of renewable energy sources generation increase and the need of maintaining a proper electrical system stability. In the next years, the phase-out of the coal will be covered by an increase of the renewable energy source exploitation supported by natural gas and biogas backup production. In this context, the production of electricity from natural gas, mainly produced by Combined Cycles Gas Turbines (CCGT) plants, that in 2019 covered $48.2 \%$ of the Italian electricity generation, will maintain its relevance at national level, even if a more flexible operating profile is envisaged. The use of Combined Cycles as backup power plants will further increase the frequency of transient operating conditions (i.e. start and stop), reducing their load factor and increasing the weight of the emissions related to transient operation with respect to those related to normal operation. In this paper, the operating profile of 45 Italian power-oriented CCGTs are analyzed showing the similarities of management in the different market zones and identifying the main operating patterns. Then a statistical analysis of the emission during normal and transient operation is performed basing on the public available yearly emission statement and highlighting the effect of the $\mathrm{CO}$ catalyzer during the transient. Finally, the yearly environmental impact of the flexible operation was assessed and compared to the yearly emission considered during the Environmental Impact Assessment, the Italian VIA (Valutazione di Impatto Ambientale).
\end{abstract}

\section{Introduction}

As a consequence of climate change mitigation goal, all around the globe, Renewable Energy Sources (RES) have been growing for the last decades and they are foreseen to increase further in order to meet the decarbonization targets at 2030 and 2050 [1]. Nevertheless, most of the newly installed RES capacity (i.e. solar PV and wind) is non-programmable and highly stochastic and the storage technologies on the grid-scale are still not ready or not sufficiently exploited [2]. Thus, we still need to have a relevant amount of backup capacity that is programmable, dispatchable, and able to provide services (i.e. balancing, frequency control, spinning reservoir) to guarantee the grid adequacy and security of power supply [3]. Because of their high efficiency in exploiting the fossil fuel energetic potential, this role is more and more often played by Combined Cycle Gas Turbine (CCGT) power plants, which have shifted from their historical duty of suppling an almost constant baseload power throughout

${ }^{*}$ Corresponding author: alessandro.sorce@unige.it 
the year, providing fluctuating back-up power to control and stabilize the grid. This is reflected in a strong reduction of their yearly operative hours and a drastic increase of startups [4].

However, the carbon footprint is not the only parameter to be taken into account to assess the environmental impact of a power plant or the whole electricity system. Many other pollutants are generated by the combustion processes: e.g. nitrogen oxides (NOx), sulfur oxides (SOx), carbon monoxide (CO), and particulate matter (PM). A CCGT power plant emits mainly NOx and CO, while SOx and PM are not relevant because there is no sulfur within the natural gas and the combustion of a gaseous fuel does not produce PM. However, the emission rate of the former two pollutants is strongly dependent on the gas turbine operating conditions: the NOx formation is favored by high combustion temperatures, thus it results to be maximized at full-load operating conditions, while the $\mathrm{CO}$ is due to an incomplete combustion process at low temperatures so it is most emitted during partial-load operating or start-ups [5]. During start-up due to the not even flow distribution, both $\mathrm{CO}$ and NOx are generated.

Therefore, the shift of the CCGTs' role observed in the last decades has an influence on the actual plant's environmental impact [6-8]. If a decrease in operating hours is obviously reflected in lower pollutant emissions, the increased occurrence of start-ups could reduce this positive effect by increasing the overall emitted pollutants' mass. To assess the sign of this balance it is needed to properly quantify the emissions even during the start-ups. This value is affected by many parameters such as the residual temperature of the Heat Recovery Steam Generator (HRSG) [7] and of the steam turbine rotor [9] that influences the start-up duration [10]. Also the gas turbine manufacturer, the power plant management itself or the presence of flue gas post-treatment technologies, (such as the Selective Catalytic Reduction, SCR, or the $\mathrm{CO}$ catalyzer for the mitigation of nitrogen oxides and carbon monoxide respectively) could affect the quantity of pollutant emitted during the transients.

To the best authors' knowledge some studies have been already carried out aiming to assess the start-up emissions, even for other technologies. Gonzalez-Salazar [7] at al. collected information from Original Equipment Manufacturers, academic research and also from power plant operators, reporting a comparison of the current and future values of specific emission factor at hot and cold starts for different technologies, according to them the emissions during a CCGT start-up are expected to be in the range of $0.02-0.9 \mathrm{~kg} / \mathrm{MW}$ for NOx and 0.1-1.8 kg/MW for CO. Suess D.T. et al. [10] reported the monitoring campaign of start-ups emissions of three General Electric gas turbines , during 18 months of operation. The study highlights a strong dependency of the emitted mass of pollutant on the transient duration showing how the emission rate $[\mathrm{kg} / \mathrm{min}]$ is almost constant while the time required to start the power plant up is strongly correlated to the standstill hours since the last shutdown. Bass R.J. et al. [11] presented experimentally measured data of NOx emitted by an $800 \mathrm{MW}$ CCGT plant monitored for 4 months, showing how the average pollutant concentration is higher for hot start-up than cold because of relevant peak $(>250 \mathrm{mg} / \mathrm{m} 3)$ during the first minutes till the parallel condition is reached. Finally, Geng Z. et al. [12] developed a NOx emission model based on CCGT data collected by the Chinese government, assuming a startup duration time between $1 \mathrm{~h}$ and $2 \mathrm{~h}$, and an emission curve whose emission rate increases from 0 up to $0.6 \mathrm{~kg} / \mathrm{min}$.

The scope of this paper is to quantify the mass of pollutants (NOx and CO) due to a CCGT start-up, or shutdown, and the related variability, identifying the most significant variables and the effectiveness of post-treatment technique during the transients. In order to accomplish this task, real data of the Italian CCGT fleet during 10 years of operation are analyzed, as described in the following section. Finally, employing these data, it is assessed how an increase of CCGT operational flexibility reflects into the local environmental impact with 
respect to the quantity estimated during the Environmental Impact Assessment (EIA) the Italian Valutazione di Impatto Ambientale (VIA).

\section{CCGT Operational Profiles}

As stated, the current context leads CCGTs to operate more and more flexibly. As reported in Fig. 1, obtained processing GME market data [13] for 2018 and 2019, in the recent years (2020 was not considered since the COVID-19 pandemic causes a strong decrease in demand for electricity), CCGTs generally operate according to four different profiles in all the Italian market zones. This chart allows to cluster the power plants on the basis of annual number of Start-Ups, SUs, and Fired Hours, FH, so on how much flexibly they operate. It is possible to identify four cluster:

- Continuous: less than $52 \mathrm{SU}$ and more than $4000 \mathrm{FH}$ annually

- Mid-Continuous: approximately $60 \mathrm{FH}$ for each SU on average

- Mid-Range: approximately $30 \mathrm{FH}$ for each SU on average

- Peaker: more than 200 SUs annually and less than 10 FH per SU

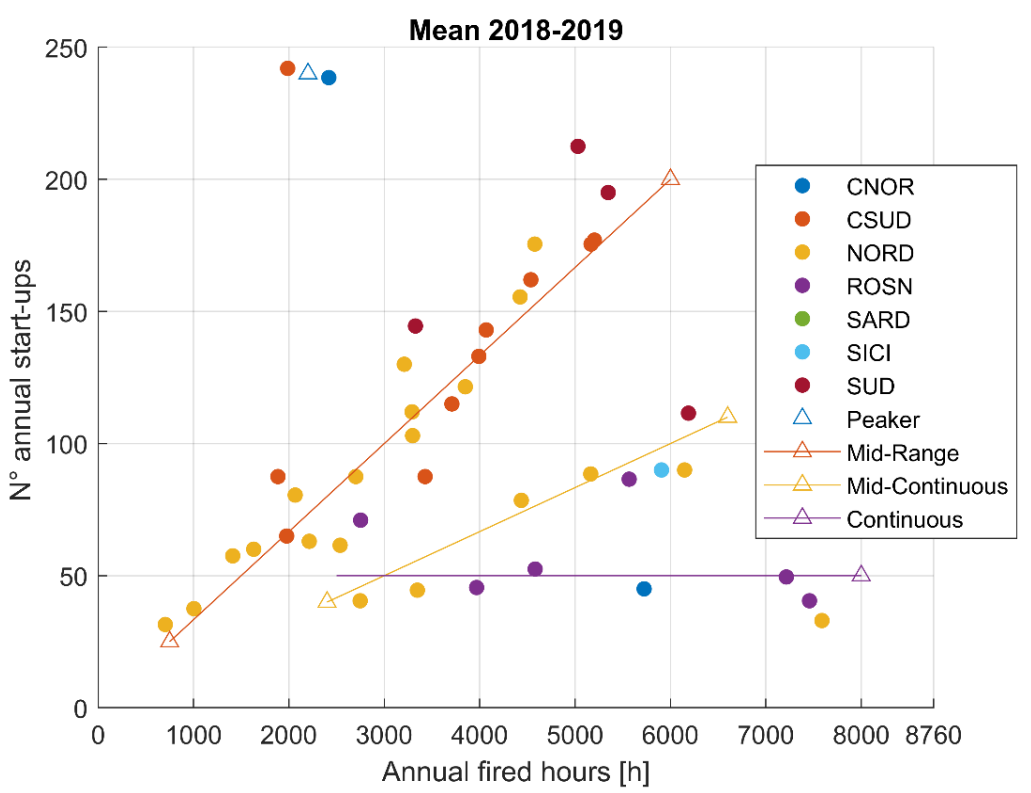

Fig. 1. Italian CCGTs' operational profiles

The scatter plot reported in Fig. 1 reports, by means of different marker's colors, the grid zone to which the power plant belongs. The Italian electricity grid is divided into zones for system security purposes, there are physical limits to transfers of electricity to/from other zones. The zones are Center-north, CNOR, Center-south, CSUD, North, NORD, Rossano, ROSN, Sardinia, SARD, Sicily, SICI, South, SUD².

Most of CCGTs operate as Mid-Range, especially for CSUD and NORD zones, which present the largest number of installed CCGT, while the Continuous power plants belong mainly to the ROSN zone. More flexible profiles i.e. peakers or mid-range, imply severe consequences on the plant's life time since during the start-up the steam turbine's rotor undergoes strong thermomechanical stresses [9]. Moreover, the transients (start-ups and shutdowns) have a stronger impact on the overall pollutant mass emitted during all the year, this paper will cover this last point. 


\section{Emissions from Combined Cycle Gas Turbine}

Italian power plants are limited within polluting elements they are allowed to emit during normal operation: the Autorizzazione Integrata Ambientale, AIA, pose a threshold, Valore Limite di Emissione, VLE, to the maximum concentration of nitrogen oxides and carbon monoxide in the exhaust. The environmental impact assessment (Valutazione di Impatto Ambientale) is carried out considering the power plant working continuously ( $8760 \mathrm{~h} / \mathrm{yr}$ ) at the VLE, and neglecting the transient contribution, this approach was highly conservative in the past, but nowadays, it could be strongly misleading since, on one hand, it overestimated the pollutant mass emitted during the real normal operating hours (since actually, the annual fired hours are less and the power plant's operator maintain a safety margin on the emission threshold during normal operation), and, on the other hand, it doesn't consider the transients at all, potentially underestimating the associated emissions.

Normal Operation FH pollutant emissions are monitored continuously by the plant manager and remotely by the public control body to ensure the respect of the VLE. On the other side, during the transients, identified by a GT load lower than the minimum environmental load (i.e. the load at which the normal operation begins), it is often not technically possible to observe the VLE limits, so the plant's manager is allowed to exceed them, but he has also the duty to monitor the flue gases composition and to communicate to the authority the overall pollutants' mass emitted during those transients within a yearly report. These reports are available on the Ecological Transition Ministry's website [14] and are used by the authors to build the dataset as described in the following section.

\subsection{Dataset}

The analysis is carried out considering only the Power Oriented, PO, power plants (i.e. exclusively devoted to power generation), since those that are devoted to the combined generation of heat and power, CHP, have to fulfill the local thermal demand, so are less affected by the flexibilization imposed by the power market. Today in Italy are currently active 45 CCGT units in 31 power plants sites, of these 28 are 1 GT +1 ST unit, 17 are $2+1$, thus the overall number of gas turbines operating in CCGT power plants is 61, Table 1 shows how those machines are distributed among the market zones. All the turbines considered are F-class with 645-715 MW thermal power input.

Table 1. Italian CCGTs ${ }^{2}$

\begin{tabular}{|l|c|c|c|c|c|}
\hline & n. sites & Public report & Detailed transients monitoring & n. CCGT units & n. GT \\
\hline NORD & 13 & 10 & 6 & 22 & 30 \\
\hline CNORD & 2 & 0 & 0 & 2 & 2 \\
\hline CSUD & 7 & 7 & 5 & 10 & 13 \\
\hline SUD & 4 & 4 & 2 & 4 & 6 \\
\hline ROSN & 4 & 4 & 0 & 6 & 8 \\
\hline SICI & 1 & 0 & 0 & 1 & 2 \\
\hline SARD & 0 & 0 & 0 & 0 & 0 \\
\hline Total & $\mathbf{3 1}$ & $\mathbf{2 5}$ & $\mathbf{1 3}$ & $\mathbf{4 5}$ & $\mathbf{6 1}$ \\
\hline
\end{tabular}

As shown by Table 1, 13 power plants attach to the report, required by the AIA, a detailed monitoring of all the GTs' transients occurred during the year. These detailed monitoring data have been collected together into a dataset in order to properly assess the environmental impact of the start-ups. Fig. 2 reports the composition of the dataset showing the number of

${ }^{2}$ The reported grid division in zones was in force until December $31^{\text {st }} 2020$, the last day included by the collected data 
transient and GT monitored for each type: GT model, owner company, year, and whether a $\mathrm{CO}$ catalyzer has been installed or not.

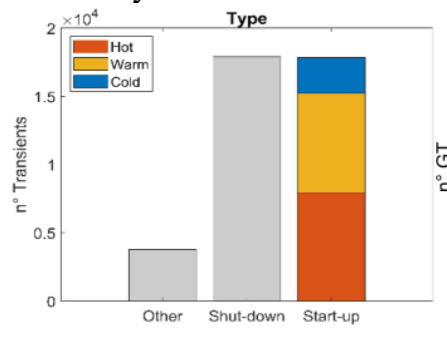

(a)

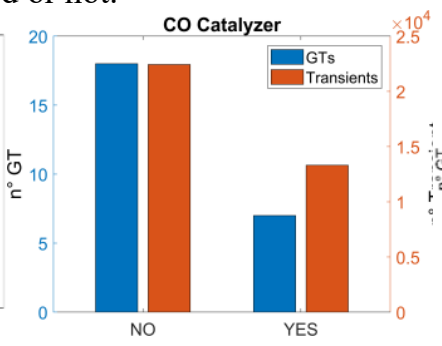

(b)

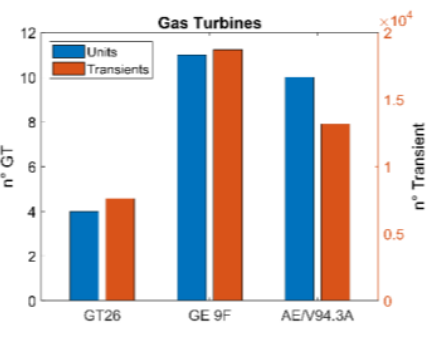

(c)

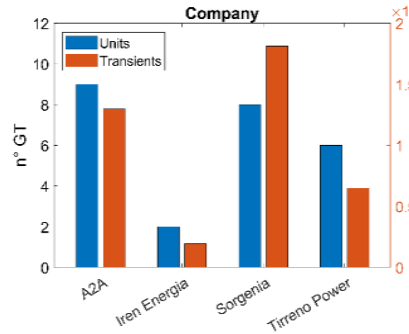

(d)

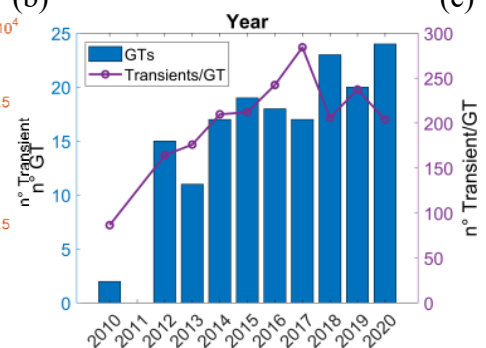

(e)

Fig. 2 : Dataset composition according to transient type (a), CO catalyzer (b), Gas turbine (c), Owner (d) and year (e). Blue bars, red bars and the purple line indicate the number of GT, the number of monitored transients and the number of transients for GT on average.

Each transient is defined as a start-up, shutdown, or other (failure start-ups, aborted shutdowns, or fluctuations below the minimum environmental load). Start-ups are defined as cold, warm, and hot, generally corresponding to more than 48 , less than 48 , less than $12-8$ Stand Still (SS) hours respectively, however, the most of report does not specify a definition for cold, warm, and hot, thus it could be not homogeneous among the considered gas turbines. This analysis and the figures from $2 \mathrm{~b}$ to $2 \mathrm{e}$ only consider start-ups and shutdown, looking at these it can be appreciated how the dataset is sufficiently large, dozens of thousands of data, to include the variability due to different plant management strategy, turbine's manufacturers, and ambient conditions. Besides, a relevant number of transients of the gas turbine with and without $\mathrm{CO}$ catalyzer, respectively 7 and 18, were monitored allowing to assess the effectiveness of this device during the transients. In Figure 2e, the trend of the number of transients per GT over the years is highlighted: after a continuous growth up to 2017 the average number of the transient appear to be stable around 220 per year equal to ca 110 SUs per year on average.

\subsection{Emission during start-up and shutdown}

Table 2 and Fig. 3 highlight the duration and the mass of pollutant emitted during the transient, data demonstrated to be sparse on such a large dataset, however, some consideration can be drawn. Generally, hot start-ups are shorter, usually, around 40 minutes, than warmer (66 minutes) and cold (93 minutes) because of the residual temperature of the rotor and the drum, the warmer they are the shorter is the time to bring the bottoming cycle's components in temperature to start the steam turbine ramp-up without compromising the plant's lifetime excessively [9]. However, some fast warm and cold SUs (around 40 minutes) appear in the database. That could be the case when the second GT of a 2+1 CCGT is started up the steam cycle is already in temperature so a shorter time is required even for a formally 
a colder start-up, so on average $2+1$ power plant could have better performance but this difference is here not investigated.

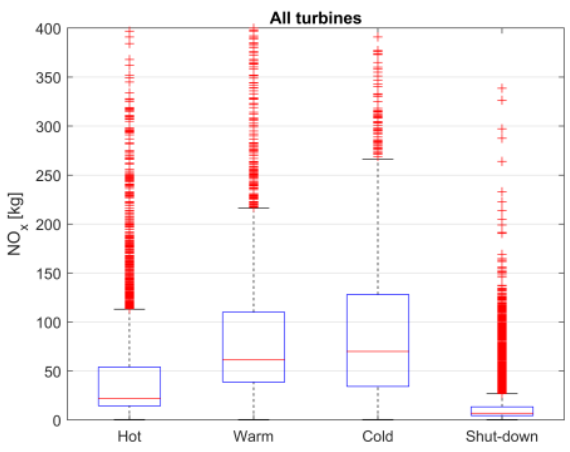

(a)

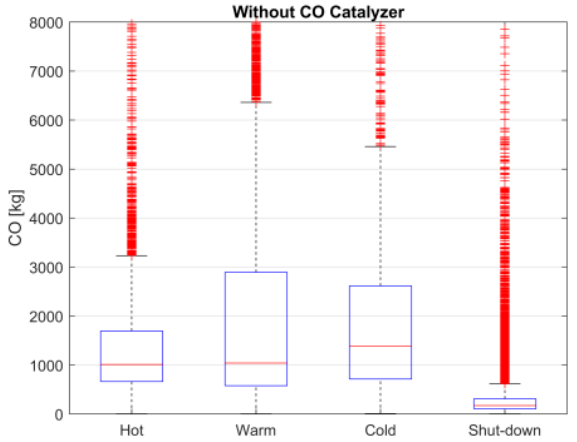

(b)

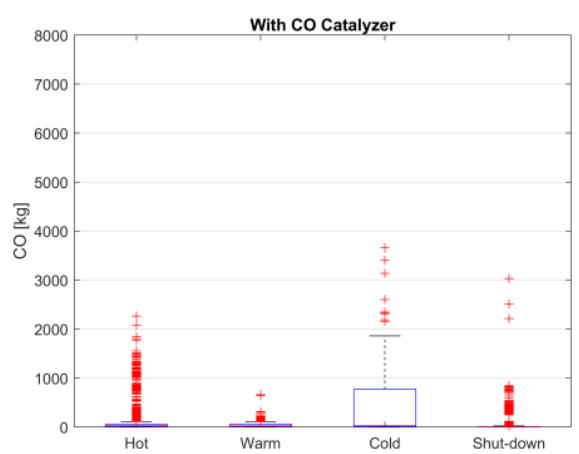

(c)

Fig. 3. Transients' pollutant mass emissions $\left[\mathrm{kg} /\right.$ transient] (a) $\mathrm{NO}_{\mathrm{x}}$, (b) $\mathrm{CO}$ without $\mathrm{CO}$ catalyzer (c) $\mathrm{CO}$ with $\mathrm{CO}$ catalyzer

The emitted mass demonstrates to be strongly correlated to the transient duration, so it can be stated that the faster the start-up, the lower the associated emission. It can be noticed that emission during transients is characterized by outliers that make the distribution positively skewed with a mean value that is always higher than the median and which often exceeds the 75 th percentile of the distribution.

Looking in general at the analyzed transients, since they occur at low temperature, the $\mathrm{CO}$ emissions tend to be prevalent, between 23 and 34 times the NOx ones in absence of CO catalyzer. On the other hand, the presence of a $\mathrm{CO}$ catalyzer allows to cut the carbon monoxide emissions by more than $95 \%$ during hot and warm SUs, and of about $86 \%$ during cold SUs. The adoption of such a secondary technique brings the $\mathrm{CO}$ emission in the same order of magnitude of the NOx (0.5-3 times).

On average the NOx emission appears to be more affected by the starting condition of the machine with a warm SU and cold SU emitting respectively 1.67 and 2.54 more than a warm $\mathrm{SU}$ on average. A ratio that is reduced to 1.15 and 1.71 when looking at the $\mathrm{CO}$ emission without $\mathrm{CO}$ catalyzer. 
Table 2. Duration and mass emissions of transients

\begin{tabular}{|c|c|c|c|c|c|c|}
\hline & & & \multicolumn{2}{|c|}{ All plants } & w/o CO & w CO \\
\hline Transients & Max SS hours & & $\begin{array}{l}\text { Duration } \\
{[\mathrm{min} / \mathrm{SU}]}\end{array}$ & $\mathrm{NO}_{x}[\mathrm{~kg} / \mathrm{SU}]$ & $\begin{array}{l}\mathrm{CO} \\
{[\mathrm{kg} / \mathrm{SU}]}\end{array}$ & $\begin{array}{l}\mathrm{CO} \\
{[\mathrm{kg} / \mathrm{SU}]}\end{array}$ \\
\hline \multirow{5}{*}{ Hot SU } & \multirow{5}{*}{$8-12$} & Mean & 52 & 42.43 & 1474.3 & 74.4 \\
\hline & & Median & 40 & 22.00 & 1012.5 & 27.4 \\
\hline & & IQ & 29 & 39.5 & 1030.7 & 39.7 \\
\hline & & $5^{\text {th }}$ Percentile & 17 & 8.70 & 143.5 & 2.66 \\
\hline & & $95^{\text {th }}$ Percentile & 123 & 125.55 & 4130.6 & 266.0 \\
\hline \multirow{5}{*}{ Warm SU } & \multirow{5}{*}{48} & Mean & 77 & 71.2 & 2196.3 & 36.1 \\
\hline & & Median & 66 & 61.39 & 1040.8 & 24.1 \\
\hline & & IQ & 41 & 71.20 & 2314.4 & 38.2 \\
\hline & & $5^{\text {th }}$ Percentile & 33 & 16.38 & 267.5 & 0.05 \\
\hline & & $95^{\text {th }}$ Percentile & 151 & 412.24 & 7895.4 & 84.6 \\
\hline \multirow{5}{*}{ Cold SU } & \multirow{5}{*}{$>48$} & Mean & 118 & 108.11 & 2524.0 & 341.9 \\
\hline & & Median & 93 & 70.00 & 1382.8 & 27.8 \\
\hline & & IQ & 90 & 93.73 & 1901.4 & 760.9 \\
\hline & & $5^{\text {th }}$ Percentile & 39 & 17.21 & 172.0 & 0.05 \\
\hline & & $95^{\text {th }}$ Percentile & 242 & 271.93 & 9747.3 & 1341.2 \\
\hline \multirow{5}{*}{ Shutdown } & \multirow{5}{*}{ - } & Mean & 16 & 13.12 & 420.3 & 23.8 \\
\hline & & Median & 15 & 7.00 & 172.2 & 4.6 \\
\hline & & IQ & 6 & 8.95 & 204.7 & 8.1 \\
\hline & & $5^{\text {th }}$ Percentile & 8 & 2.32 & 19.3 & 0.05 \\
\hline & & $95^{\text {th }}$ Percentile & 28 & 37.88 & 1790.9 & 37.1 \\
\hline
\end{tabular}

\subsection{Normal operating Fired Hours emissions}

Looking at the publicly available information in the AIA for the power plants included in this analysis the VLE is in the range of $24 \mathrm{mg} / \mathrm{Nm}^{3}$ to $50 \mathrm{mg} / \mathrm{Nm}^{3}$, the modal value is $30 \mathrm{mg} / \mathrm{Nm}^{3}$ both for $\mathrm{NO}_{\mathrm{x}}(72 \%)$ and $\mathrm{CO}(82 \%$ of the GTs of Table 3$)$ on an hourly basis, equal to 55.63 $\mathrm{kg} / \mathrm{h}$ for F-class machines as the ones under assessment in this work. This number can be compared with the actual data published annually in the reports by the CCGT operators. In fact, each report provides the amount of annual fired hours and the pollutant mass emitted during this period of normal operation. Processing these data, the values reported in Table 3 are obtained.

Table 3. Normal operating hours emissions of the 25 power plants sites publishing yearly reports

\begin{tabular}{|c|c|c|c|}
\hline & All & w CO cat. & w/o CO cat. \\
\hline & $\mathrm{NO}_{\mathrm{x}}$ & $\mathrm{CO}$ & $\mathrm{CO}$ \\
\hline Mean $[\mathrm{kg} / \mathrm{h}]$ & 29.86 & 4.40 & 3.11 \\
\hline Median $[\mathrm{kg} / \mathrm{h}]$ & 30.46 & 2.89 & 2.91 \\
\hline IQR $[\mathrm{kg} / \mathrm{h}]$ & 11.67 & 2.70 & 3.57 \\
\hline $5^{\text {th }}$ Percentile $[\mathrm{kg} / \mathrm{h}]$ & 10.64 & 0.75 & 0.89 \\
\hline $95^{\text {th }}$ Percentile $[\mathrm{kg} / \mathrm{h}]$ & 41.70 & 6.69 & 11.71 \\
\hline VLE $[\mathrm{kg} / \mathrm{h}]$ & 55.63 & 55.63 & 55.63 \\
\hline Mean/VLE [\%] & 53.7 & 7.9 & 5.6 \\
\hline
\end{tabular}

It must be noted as on average the CCGT emit just $53.7 \%$ of the amount of allowed emission per hour of $\mathrm{NOx}$ and just between $5.6 \%$ and $7.9 \%$ of the $\mathrm{CO}$ during normal operating hours, since carbon monoxide become relevant just to the low load condition.

It is very interesting to underline that there is almost no difference in $\mathrm{CO}$ emissions between those units having a CO catalyzer and those that have not. In fact, the main reason 
for which a CO catalyzer is installed is to lower the Minimum Environmental Load, MEL, (i.e. the minimum load which allows to fully respect the carbon monoxide VLE). A lower MEL is reflected in many benefits such as the ability in saving fuel, and so in cutting CO2 emissions, or in providing reserve capacity and services to the grid, but it does not follow directly a decrease in $\mathrm{CO}$ emission during normal operating hours: at intermediate and full load the catalyzer could reduce the $\mathrm{CO}$ but small quantities are in the flue gas, while probably it works more frequently at the minimum load emitting almost the VLE as well as without catalyzer.

\section{Flexible Environmental Impact Assessment}

This section proposes an approach to properly assess the environmental impact considering the real flexible operating profiles. Since a real power plant performs many start-ups hot, warm, and cold, the mean value of all the start-ups data presented in section 2 has been assumed as the representative of the average Italian CCGT for the pollutant mass emitted during the start-up. Moreover, the average value of shutdowns has been added, obtaining for each SU/SD cycle $90.02 \mathrm{~kg}$ of NOx, $136.9 \mathrm{~kg}$, and $2405.5 \mathrm{~kg}$ of CO for a turbine with and without $\mathrm{CO}$ catalyzer respectively. For the normal operating emissions, average data presented in section 3 have been used analogously.

In the next figures, iso-emission black dashed lines, are superimposed to the CCGT operating profile in order to highlight the impact of the different management strategies. The plotted iso-emission lines correspond to different percentage of the pollutant mass considered by the VIA, so that it is easy to check whether this assessment overestimates or underestimates the real emission of the pollutant.

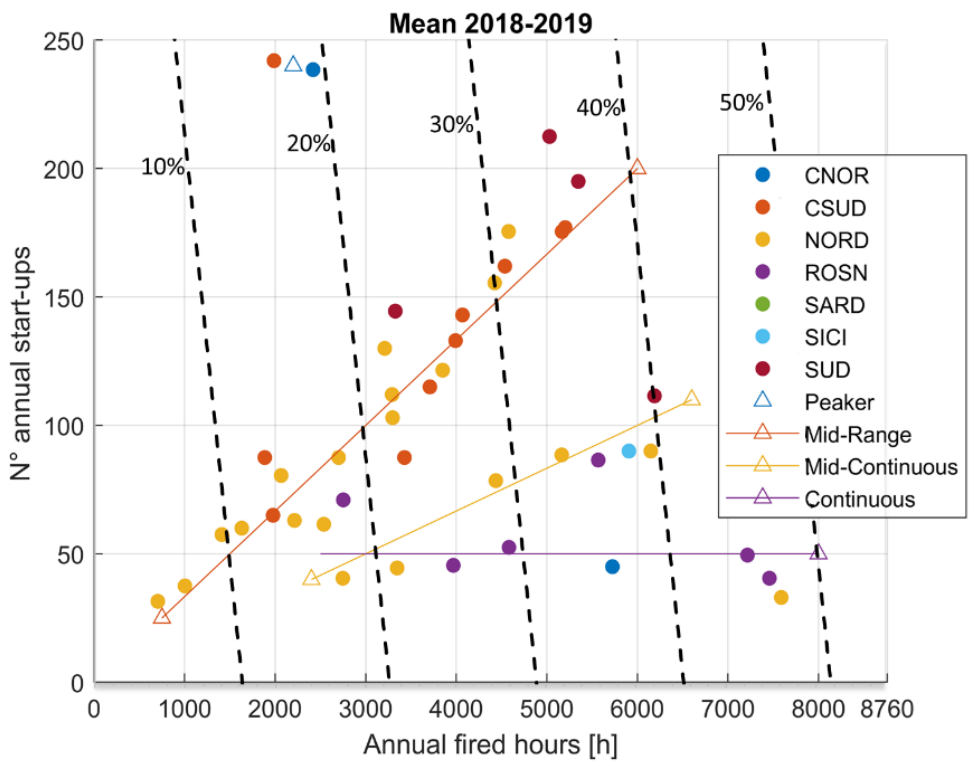

Fig.4 $\mathrm{NO}_{\mathrm{x}}$ annual emission black dashed lines: percentage ratio of annual emission against annual VIA emission

Fig. 4 shows how ISO emissions lines for $\mathrm{NO}_{\mathrm{x}}$ are very steep, as $1 \mathrm{SU} / \mathrm{SD}$ cycle is equivalent to 3 fired hours, then the assessment carried out according to the VIA approach always overestimate the real power plants $\mathrm{NO}_{\mathrm{x}}$ emission, those continuous power plants operating more than $7000 \mathrm{~h} / \mathrm{yr}$ emits only the $45 \%$ of what has been estimated by the VIA. 


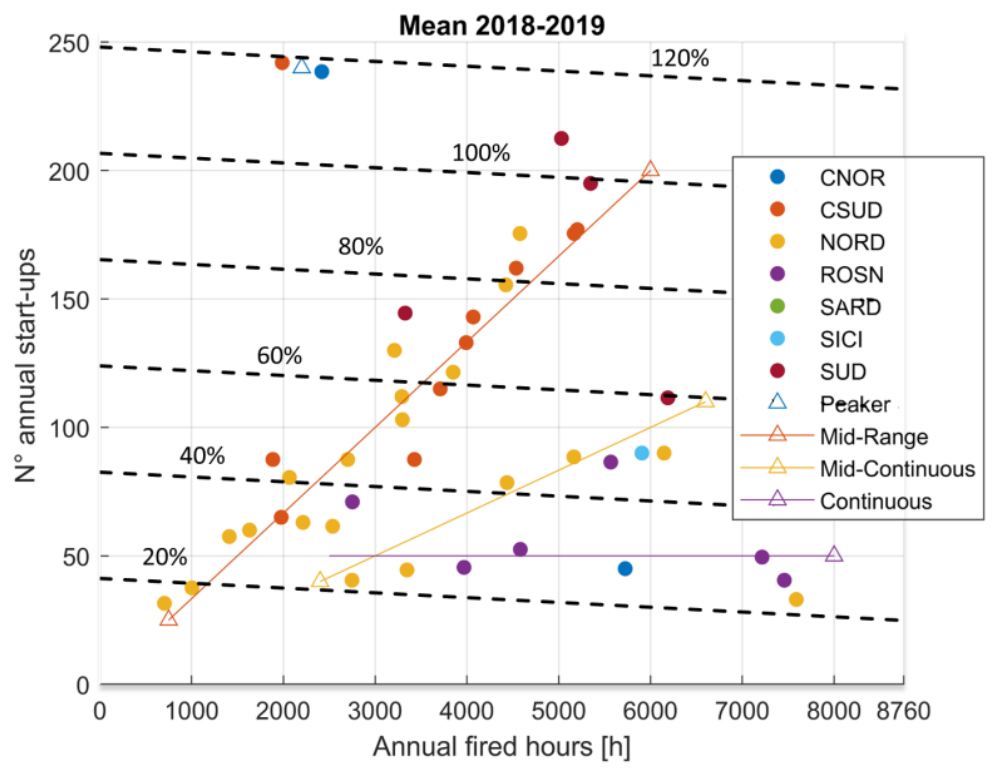

Fig. $5 \mathrm{CO}$ annual emission without $\mathrm{CO}$ catalyzer: black dashed lines: percentage ratio of annual emission against annual VIA emission

Furthermore, it should be noted how the iso-emissions are almost flat since most of CO is emitted during the start-ups, $1 \mathrm{SU} / \mathrm{SD}$ cycle is equivalent to 546 fired hours in terms of emitted mass. So, carbon monoxide could be critical for those CCGTs working with frequent SU. Fig. 5 highlights how, if most of CCGTs $(<110 \mathrm{SU})$ emit less than $50 \%$ of the CO that has been estimated by the VIA, the peakers (i.e. those CCGTs performing more than 200 $\mathrm{SU} / \mathrm{SD}$ cycles per year) are expected to emit more.

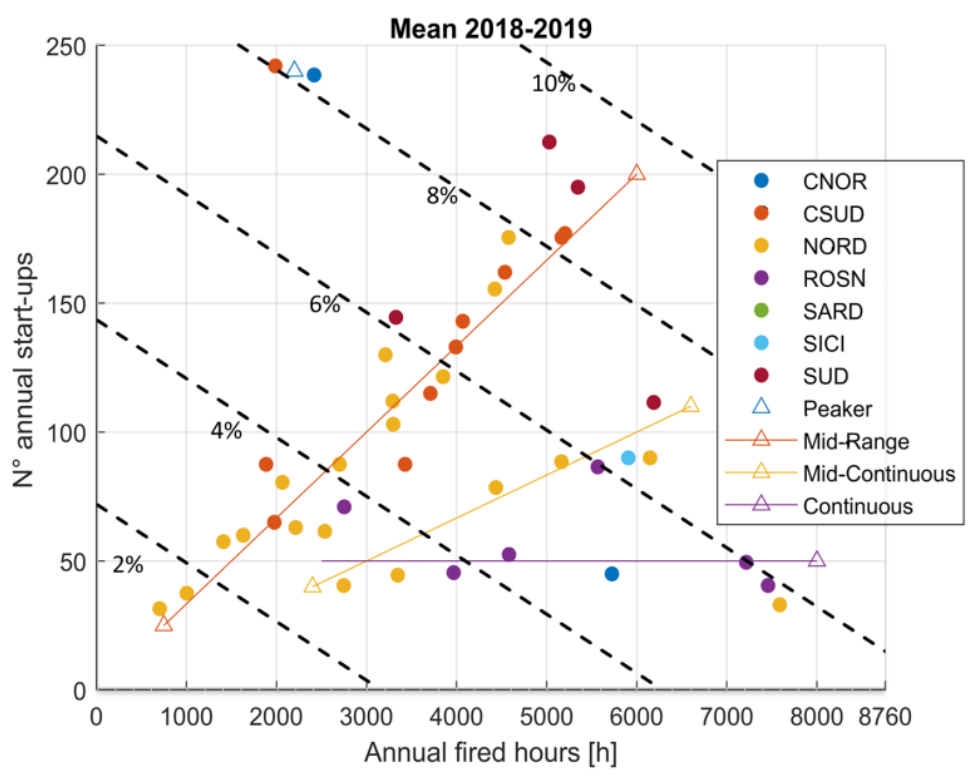

Fig.6 CO annual emission with CO catalyzer: black dashed lines: percentage ratio of annual emission against annual VIA emission 
Nevertheless, according to Fig. 6, the peakers are expected to emit less than $10 \%$ of what estimated by the VIA if they installed a CO catalyzer. As seen in the previous sections this device has no impact on the normal operating hours emission, but it could drastically cut the start-ups' emission of CO since in this case a SU/SD is equivalent to 44 fired hours in terms of emissions, so those devices can be effectively used to eliminate the impact of a more frequent start-up even in the future energy transition.

\section{Conclusion}

This paper presented the process of collection and analysis of public data from the Italian CCGT fleet. Those data have been merged into a manifold dataset with the purpose of properly assessing the environmental impact of real power plants under flexible operation and performing a relevant number of annual SU/SD. The analysis focused on nitrogen oxides and carbon monoxide, showing how the different start-up procedures (hot, warm, cold) affect the emission.

Looking at the annual pollutant emission, the $\mathrm{CO}$ one could be negatively affected by flexible operation of CCGTs, since most of the pollutant mass is emitted during the start-ups (a start-up is equivalent to 546 fired hours). For those CCGTs performing more than 200 start-ups per year the mass of $\mathrm{CO}$ emitted could exceed the quantity assessed during the institutional environmental impact assessment (VIA). It must be stressed that this not imply an environmental problem since the quantity evaluated the $\mathrm{CO}$ is not a critical pollutant under the air quality point of view (no values exceed the quality value across Europe), however, this must be taken into account to perform the VIA process under more realistic assumptions. For such a high number of SU, in any case, the CO catalyzer demonstrated to be an effective solution to mitigate the startups' emissions and it should be considered when the yearly startup number approaches 200 .

It has not been possible to assess the effectiveness of post-treatment technologies for NOx mitigation as well, since none of the CCGTs included in the analysis have installed a Selective Catalytic Reactor, anyway the NOx emissions are not negatively affected by frequent SUs and SDs, since the most is emitted during normal operating hours, and the Environmental Impact Assessment is very conservative in estimating the annual mass NOx emissions, since all the Italian CCGTs emit (less than the 50\%), a value that is expected to decrease with the reduction of operative hours envisaged with the future energy transition.

Finally, besides being able to reduce the carbon footprint of the programmable power plant thanks to the high efficiency and the use of lower (natural gas) or neutral carbon footprint fuels, the Combined Cycles can support the energy transition without increasing their environmental impact at the local scale.

\section{References}

1. IEA, Renewables 2020 - Analysis and Forecast to 2025 (Paris, 2020)

2. A. Castillo and D. F. Gayme, Energy Convers. Manag. 87, 885 (2014)

3. Mid-Term Adequacy Forecast - Executive Summary (2020)

4. W. Broos, in ETN Congr. Oct. 14, 2014 (2014)

5. A. H. Lefebvre and D. R. Ballal, Gas Turbine Combustion Alternative Fuel and Emissions, 3rd editio (CRC Press, 2010)

6. R. Turconi, C. O’Dwyer, D. Flynn, and T. Astrup, Appl. Energy 131, 1 (2014)

7. M. A. Gonzalez-Salazar, T. Kirsten, and L. Prchlik, Renew. Sustain. Energy Rev. 82, 1497 (2018)

8. J. Blondeau and J. Mertens, J. Clean. Prod. 221, 261 (2019) 
9. I. Rossi, A. Sorce, and A. Traverso, Appl. Energy 190, (2017)

10. D. T. Suess, E. A. Suess, and S. R. Gregory, in Proc. Air Waste Manag. Assoc. Annu. Conf. Exhib. AWMA (2009), pp. 3232-3248

11. R. J. Bass, W. Malalasekera, P. Willmot, and H. K. Versteeg, Energy 36, 1956 (2011)

12. Z. Geng, S. Member, Q. Chen, S. Member, Q. Xia, S. Member, D. S. Kirschen, C. Kang, and S. Member, IEEE Trans. Power Syst. 32, 127 (2017)

13. (n.d.)

14. (n.d.)

\section{Nomenclature}

\section{Abbreviations and Acronyms}

AIA Autorizzazione Integrata Ambientale (IPCC Permit)

CCGT Combined Cycle Gas Turbine

Cat. Catalizer

CHP Combined Heat and Power

$\mathrm{CO} \quad$ Carbon Monoxide

FH Fired Hours

GME Gestore Mercati Energetici

GT Gas Turbine

$\mathrm{NO}_{\mathrm{x}} \quad$ Nitrogen Oxide

PM Particulate Matter

PO Power Oriented

RES Renewable Energy Sources

SCR Selective Catalysis Reduction

SD Shutdown

SOx Sulfur Oxide

ST Steam Turbine

SU Start-up

IQR Inter Quartile Range

SS Stand Still

SU Start-up

VIA Valutazione Impatto Ambientale (Environmental Impact Assessment)

VLE Valore Limite Emissione (Thershold Emission Levels) 